\title{
Temperature Effect over Gas Bubble Evolution in Uranium-10 wt.\% Molybdenum alloy Irradiated by Swift Xe lons
}

Chemical and Fuel Cycle Technologies Division 


\title{
About Argonne National Laboratory
}

Argonne is a U.S. Department of Energy laboratory managed by UChicago Argonne, LLC under contract DE-AC02-06CH11357. The Laboratory's main facility is outside Chicago, at 9700 South Cass Avenue, Lemont, Illinois 60439. For information about Argonne and its pioneering science and technology programs, see www.anl.gov.

\section{DOCUMENT AVAILABILITY}

Online Access: U.S. Department of Energy (DOE) reports produced after 1991 and a growing number of pre-1991 documents are available free at OSTI.GOV (http://www.osti.gov/), a service of the U.S. Dept. of Energy's Office of Scientific and Technical Information.

\author{
Reports not in digital format may be purchased by the public from the \\ National Technical Information Service (NTIS): \\ U.S. Department of Commerce \\ National Technical Information Service \\ 5301 Shawnee Rd \\ Alexandria, VA 22312 \\ www.ntis.gov \\ Phone: (800) 553-NTIS (6847) or (703) \\ 605-6000 Fax: (703) 605-6900 \\ Email: orders@ntis.gov
}

\section{Reports not in digital format are available to DOE and DOE contractors from the Office of Scientific and Technical Information (OSTI):}

U.S. Department of Energy

Office of Scientific and Technical Information

P.O. Box 62

Oak Ridge, TN 37831-0062

www.osti.gov

Phone: (865) 576-8401

Fax: (865) 576-5728

Email: reports@osti.gov

Disclaimer

\section{Disclaimer}

This report was prepared as an account of work sponsored by an agency of the United States Government. Neither the United States Government nor any agency thereof, nor UChicago Argonne, LLC, nor any of their employees or officers, makes any warranty, express or implied, or assumes any legal liability or responsibility for the accuracy, completeness, or usefulness of any information, apparatus, product, or process disclosed, or represents that its use would not infringe privately owned rights. Reference herein to any specific commercial product, process, or service by trade name, trademark, manufacturer, or otherwise, does not necessarily constitute or imply its endorsement, recommendation, or favoring by the United States Government or any agency thereof. The views and opinions of document authors expressed herein do not necessarily state or reflect those of the United States Government or any agency thereof, Argonne National Laboratory, or UChicago Argonne, LLC. 
ANL/CFCT-20/28

\section{Temperature Effect over Gas Bubble Evolution in Uranium-10 wt.\% Molybdenum alloy Irradiated by Swift Xe lons}

prepared by

Sumit Bhattacharya, Yinbin Miao, Kun Mo, Laura Jamison, Heather Connaway, and Abdellatif Yacout

Chemical and Fuel Cycle Technologies Division, Argonne National Laboratory

June 2021 
(This page left intentionally blank) 


\section{Abstract}

Results from post-irradiation examination (PIE) of U-10Mo binary metallic fuel irradiated by 84 $\mathrm{MeV}$ Xe ions at two different temperatures $\left(450^{\circ} \mathrm{C} \& 275^{\circ} \mathrm{C}\right)$ have been evaluated and reported. The main goal of this study was to understand gas bubble formation (due to accumulation of Xe gas) and corresponding size evolution dependent upon net Xe deposition at two different temperatures, for the U-10Mo fuel samples. From the post ion irradiation examination analysis, it can be concluded that at $450^{\circ} \mathrm{C}$ the $\mathrm{Xe}$ gas bubbles seems to coarsen more easily compared to $275^{\circ} \mathrm{C}$. The results of ion irradiation testing can provide initial data that may be beneficial for fuel system down-selections, and for the development and validation of fuel performance models. 


\section{Table of Contents}

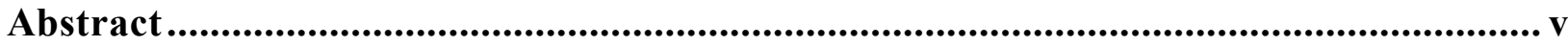

Table of Contents ................................................................................................................ vi

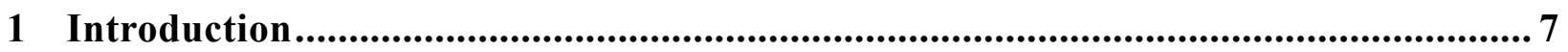

2 Experimental Procedure ...................................................................................................... 7

2.1 Samples and Swift Ion Irradiation ............................................................................ 7

2.2 Post-Irradiation Examination Methods ……………................................................... 9

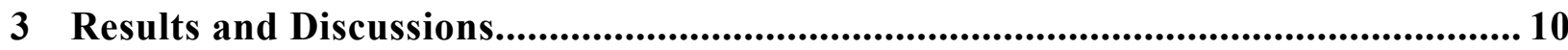

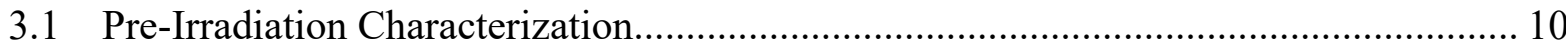

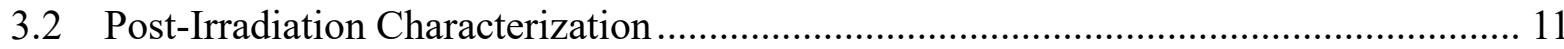

3.2.1 Bubble Evolution at Temperature, $450^{\circ} \mathrm{C}$........................................................ 11

3.2.1.1 Bubble Size Distribution and Density in Region 1 .............................. 15

3.2.1.2 Bubble Size Distribution and Density in Region 2 2.............................. 16

3.2.1.3 Bubble Size Distribution and Density in Region 3 ............................... 17

3.2.1.4 Bubble Size Distribution and Density in Highest Xe Deposition Region of U-10Mo Specimen .................................................................................... 17

3.2.2 Bubble Evolution at Temperature, $275^{\circ} \mathrm{C}$....................................................... 19

4 Future Work

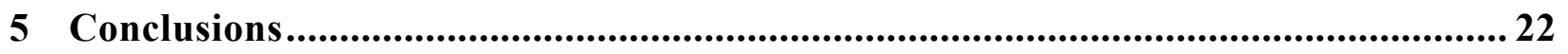

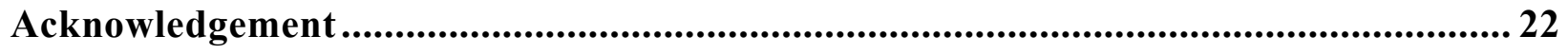

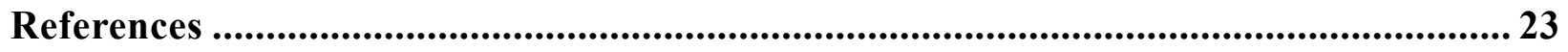




\section{Introduction}

The post-irradiation examination (PIE) results of U-10Mo binary metallic fuel that was irradiated by $84 \mathrm{MeV} \mathrm{Xe}$ ions at two different temperatures $\left(450^{\circ} \mathrm{C} \& 275^{\circ} \mathrm{C}\right)$ are reported here. Ion irradiation testing can provide initial data that may be beneficial to down-selection, or to support of other technical decisions. This data can also provide valuable references for the development and validation of fuel performance models for this fuel.

The as-fabricated U-10Mo used for performing this heavy ion irradiation testing has a BCC crystal structure with an inhomogeneous microstructure. The main goal of this study was to understand gas bubble formation (due to accumulation of Xe gas) and corresponding size evolution dependent upon net Xe deposition at two different temperatures. After irradiation by $84 \mathrm{MeV} \mathrm{Xe}$ ions at $450^{\circ} \mathrm{C} \& 275^{\circ} \mathrm{C}$ to reach up to $5.8 \mathrm{E}+17$ ions $/ \mathrm{cm} 2$ fluence or $3.0 \%$ equivalent burnup the quantitative bubble morphology data has been collected and presented in detail for $450^{\circ} \mathrm{C}$ and some preliminary results for the irradiation study performed at $275^{\circ} \mathrm{C}$.

\section{Experimental Procedure}

\subsection{Samples and Swift Ion Irradiation}

Swift ions are implanted into the samples in one direction (exposed side), form a radiation damage and foreign atom deposition profile as a function of depth. Hence, the radiation dose can be computed from the provided surface depth. In order to produce irradiated specimens with a welldefined radiation dose, mechanically polished U-10Mo monolithic discs were directly utilized in this study. The swift ion irradiation was conducted at Argonne Tandem Linac Accelerator System (ATLAS) at Argonne National Laboratory $[1,2]$. Three individual U-10Mo monolithic discs were mounted on each of three separate sample stages made out of oxygen-free high conductive (OFHC) copper using PELCO high conductivity silver paste. A Heatwave Lab. TB-175 cartridge heater was also fastened on each sample stage to provide a heat source when elevated irradiation temperature is needed (especially for higher temperature experiments). Detailed ion irradiation 
sample stage used for this particular experiment can be found in Figure. 1. An $84 \mathrm{MeV}$ Xe ion beam was used to irradiate these samples at two different temperatures: $450^{\circ} \mathrm{C} \& 275^{\circ} \mathrm{C}$. The ion beam has an approximate 2D Gaussian profile with a $\sigma x$ parameter of $1.47 \mathrm{~mm}$, a $\sigma y$ parameter of $2.19 \mathrm{~mm}$, and a current of 600 particle nano-ampere (pnA). More detailed irradiation condition information can be found in Table 1 .

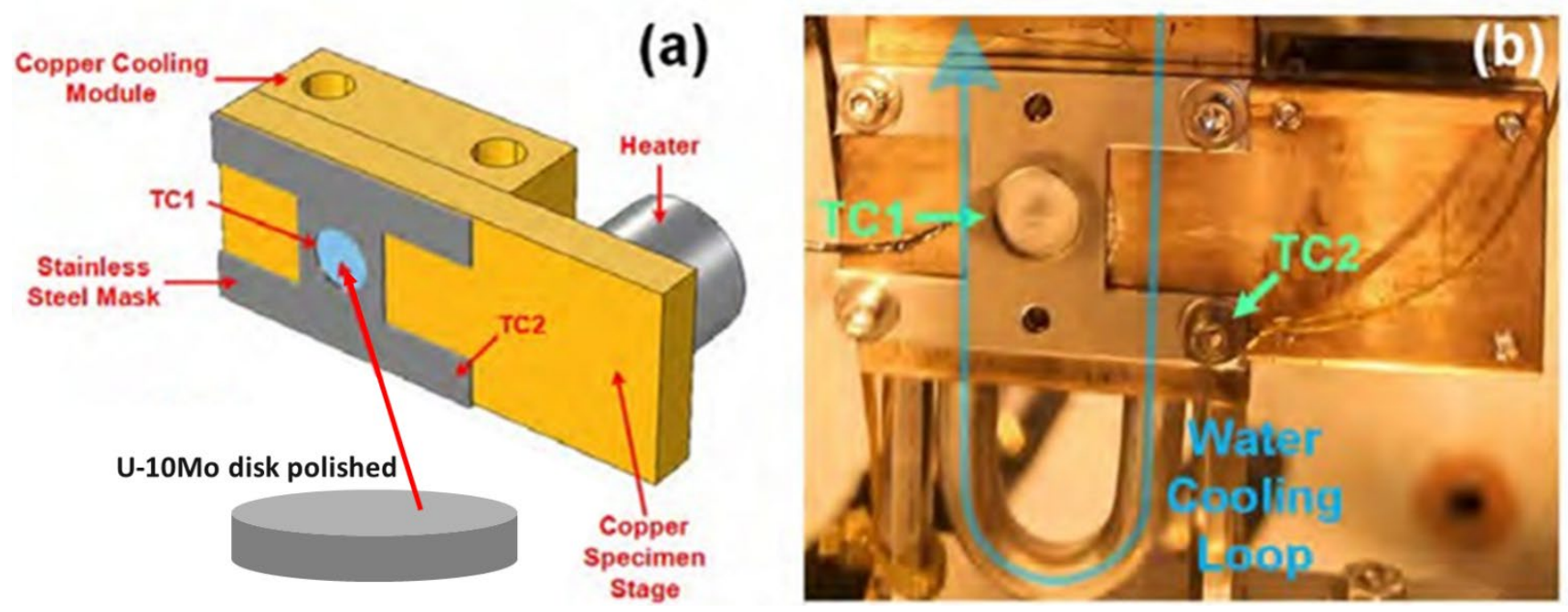

Figure 1: Setup of the swift ion irradiation experiment: (a) a schematic drawing of the ion irradiation stage used in this study; (b) a photographic image of the ion irradiation stage.

Table 1: Radiation conditions of the U-10Mo specimens investigated in this study.

\begin{tabular}{|c|c|c|c|c|c|}
\hline Materials & $\begin{array}{c}\text { Temp } \\
\left({ }^{\circ} \mathbf{C}\right)\end{array}$ & $\begin{array}{c}\text { Current } \\
(\mathbf{p n A})\end{array}$ & $\begin{array}{c}\text { Max Dose } \\
\left(\mathbf{i o n s} / \mathbf{c m}^{2}\right)\end{array}$ & $\begin{array}{c}\text { Eq. BU } \\
\text { (DPA, } \\
\text { peak/avg) }\end{array}$ & Time (Hour) \\
\hline \multirow{2}{*}{ U-10Mo } & $\sim 450$ & 600 & $5.8 \mathrm{E}+17$ & $3.0 \% / 1.1 \%$ & $\sim 11$ \\
\cline { 2 - 6 } & $\sim 275$ & 600 & $5.8 \mathrm{E}+17$ & $3.0 \% / 1.1 \%$ & $\sim 11$ \\
\hline
\end{tabular}


The radiation dose and deposited Xe profiles of the $84 \mathrm{MeV}$ Xe ions in the U-10Mo specimens were calculated using SRIM [3] according to Stoller et al.'s guideline [3] with the following displacement energies $\left(E^{U}=35.6 \mathrm{eV}\right.$ [4], and $E^{M o}=60.0 \mathrm{eV}$ [5]. The results are illustrated in Fig. 2. It is clear that the peak radiation damage occurs near 4.85 micrometer from the surface, whereas the overwhelming majority of the Xe atoms were deposited at $\sim 5.25$ micrometer. During the ion irradiation, the temperature fluctuation was limited within $\pm 5{ }^{\circ} \mathrm{C}$, except for some occasional beam interruption.

\subsection{Post-Irradiation Examination Methods}

The gas bubble formation within these irradiated U-10Mo binary metallic fuels were first examined using scanning electron microscopy (SEM). In order to expose the cross-sections of the specimens, focused ion beam (FIB) was used to mill these irradiated specimens. An FEI Strata 400 SEM-FIB Dual Beam system, which has a Ga-ion FIB source and a field emission gun (FEG) electron source, was adopted for the SEM investigation. A systematic study of the gas bubble distribution along the damage plane correlated with Xenon deposition at two different temperatures was performed. Two thin foil specimens were lifted out from the irradiated U-10Mo binary metallic fuels using an FEI Quanta 3D FEG scanning electron microscope/focused ion beam (SEM/FIB) Dual Beam system. Both samples were prepared with materials dug from the center of the ion beam footprint which received maximum dosage. These two lamellae were mounted on top of a copper Omniprobe TEM grid using the Pt deposition available in the Dual Beam system. Two rectangular areas of approximately $10 \mu \mathrm{m}$ (width) $\times 10 \mu \mathrm{m}$ (depth) on the HD foil were further thinned to electron transparency (approximately $100 \mathrm{~nm}$ ) by the FIB. These three thin areas were cleaned by $5 \mathrm{keV}$ and $2 \mathrm{keV}$ Ga ions to minimize the artificial radiation damage induced by FIB. TEM characterizations were conducted on a Hitachi 9000 in IVEM facility at ANL. A series of imaging techniques, including TEM bright-field (BF) diffraction contrast imaging was utilized to investigate the microstructure modifications and gas bubble evolution induced by Xe ions 


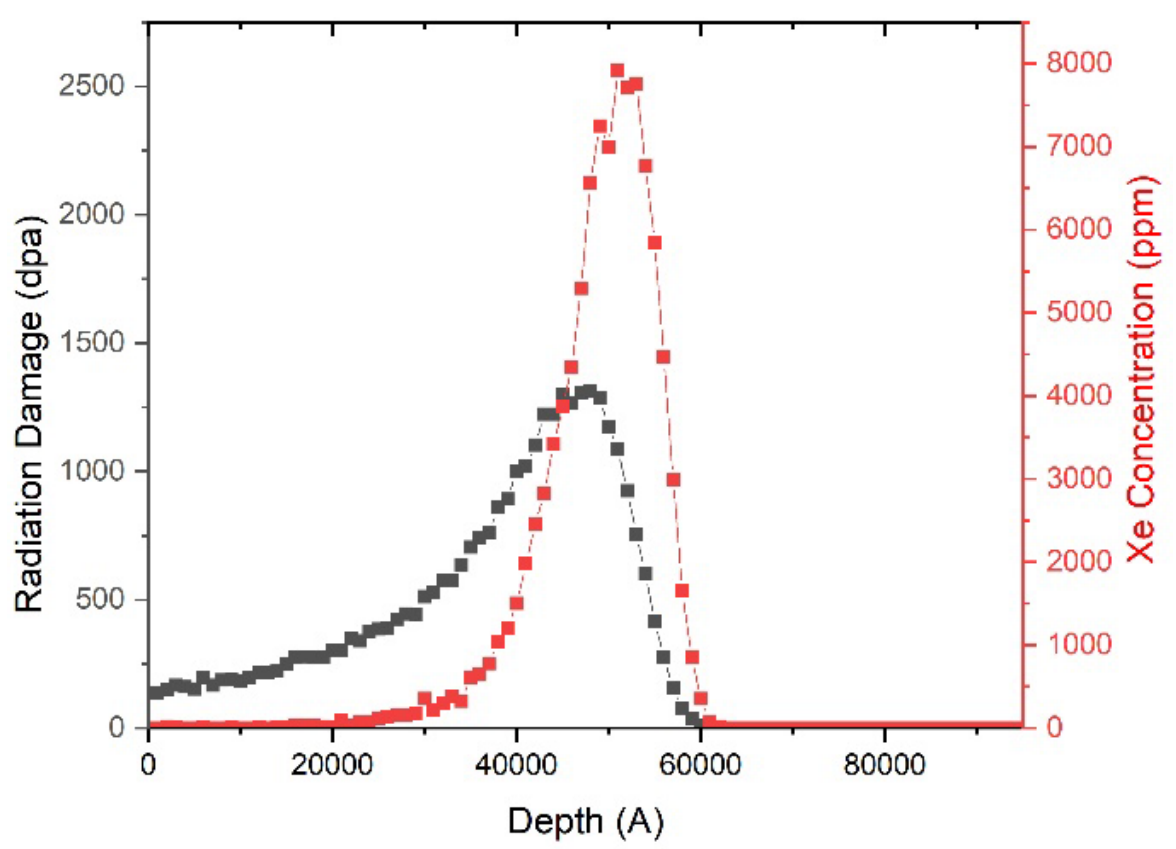

Figure 2: Xe deposition and radiation dose profile calculated by SRIM

\section{Results and Discussions}

\subsection{Pre-Irradiation Characterization}

Characterization was performed to document the U-10Mo microstructure before irradiation was performed, such that any changes after irradiation are identified. Figure 3 shows the typical morphology and sub-surface condition of the U-10Mo disc prior to irradiation. From BSE image of the cross section, the U-10Mo does not have a homogeneous matrix unlike what is seen in other published work [3]. 


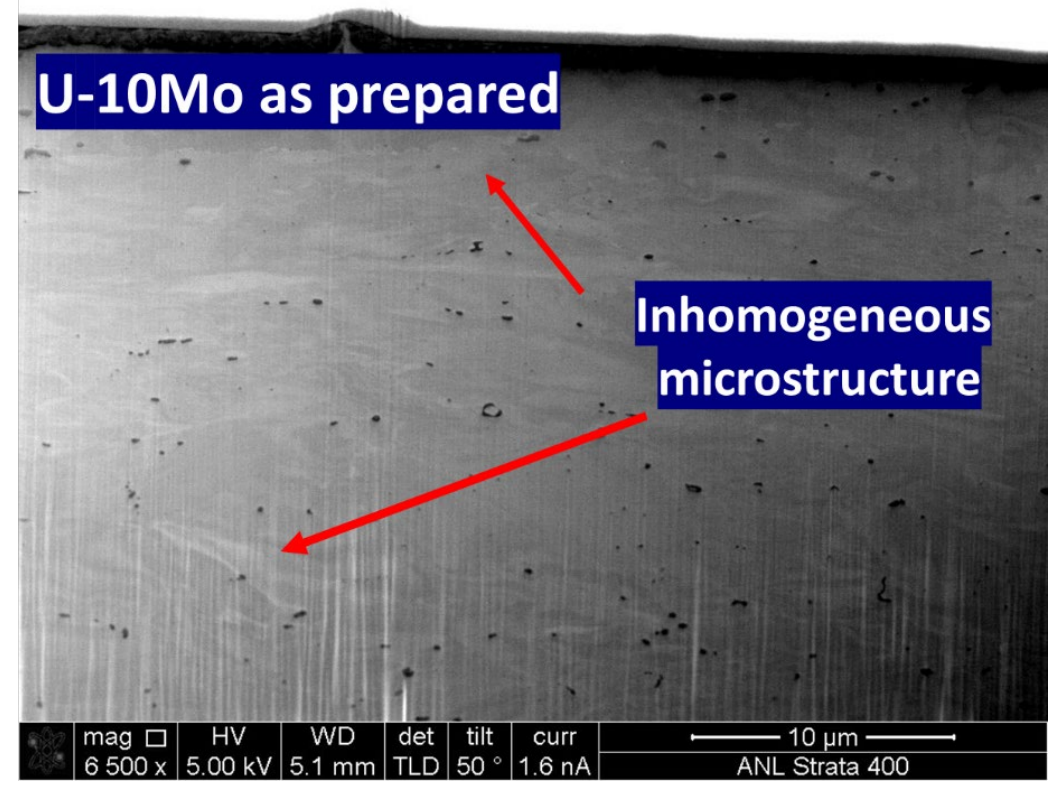

Figure 3: FIB cross section of U-10 Mo. Based on the BSE image it seems the matrix do not have a homogeneous matrix.

\subsection{Post-Irradiation Characterization}

\subsubsection{Bubble Evolution at Temperature, $450^{\circ} \mathrm{C}$}

The overall microstructure for the U-10Mo binary metallic fuel specimen is shown in figure 4. During analysis, diffractions rings identified as uranium oxide started to become prominent, especially in the highest Xe deposition zone. Such oxidations may have been a result of the brief exposure of the $\sim 15 \mathrm{~nm}-40 \mathrm{~nm}$ thick air sensitive U-10Mo specimen to ambient conditions or as a result of oxygen getter behavior of uranium within the TEM itself. The dark layer on the top of the TEM thinned foil is a result of oxidation during Xe ion irradiation process. Such surface oxidation has been found to be common in uranium systems under ion irradiation. With help of SADP analysis, the orientation of the two- grains marked as grain 1 and 2 (dark blue), have been identified. Grain 1 has a [113] orientation while Grain 2 has a [210] orientation. From SADP analysis the crystal structure of the system is also identified as base centered cubic (BCC). 


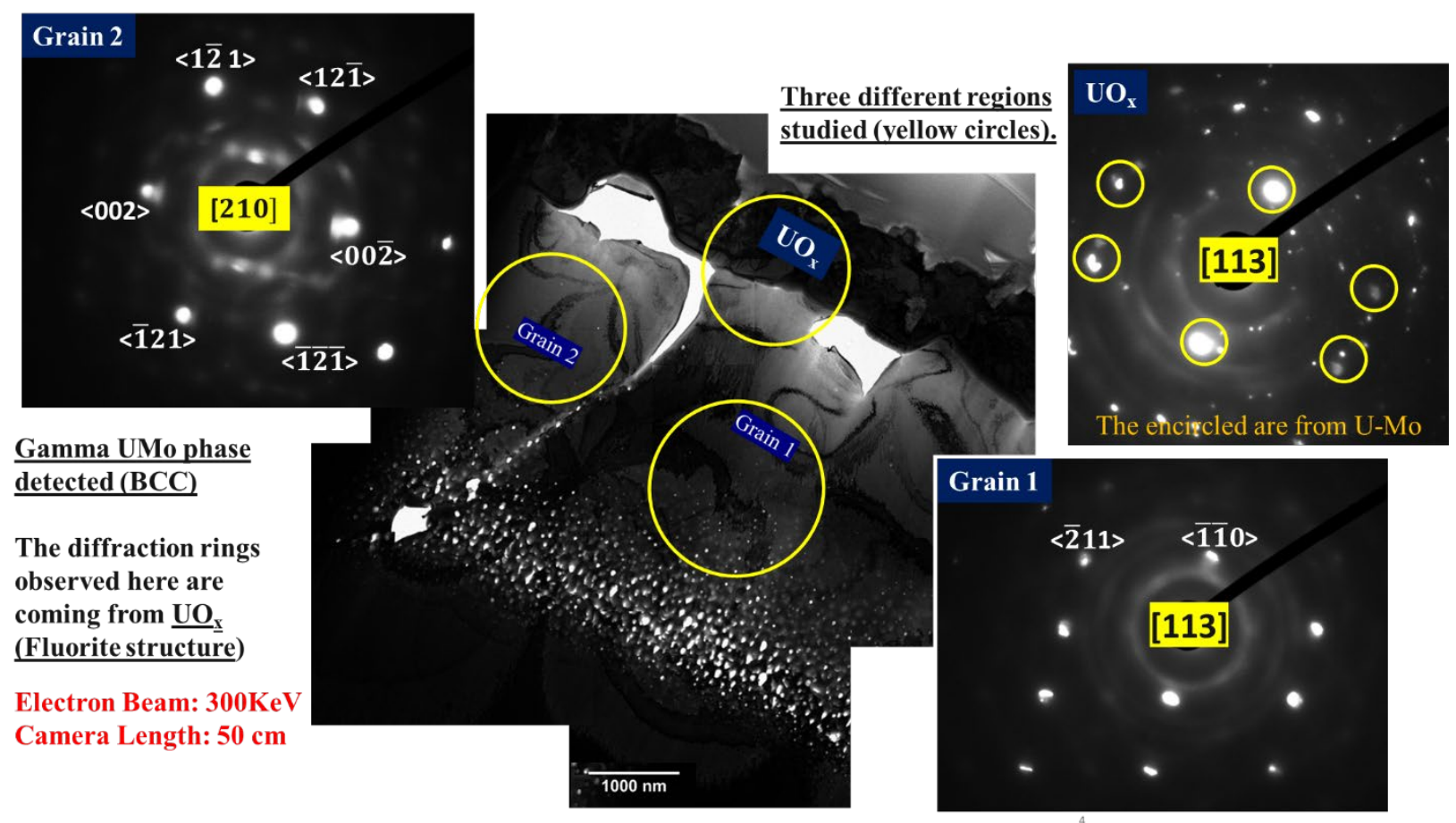

Figure 4: Detailed SADPs of the two visible grains in the bright field image of the TEM foil identified as Grain 1 and Grain 2. From detailed analysis it is found that the orientation of these two grains are [ $\left[\begin{array}{lll}1 & 1 & 3\end{array}\right]$ and $\left[\begin{array}{lll}2 & 1 & 0\end{array}\right]$ respectively belongs to a BCC crystal structure. 


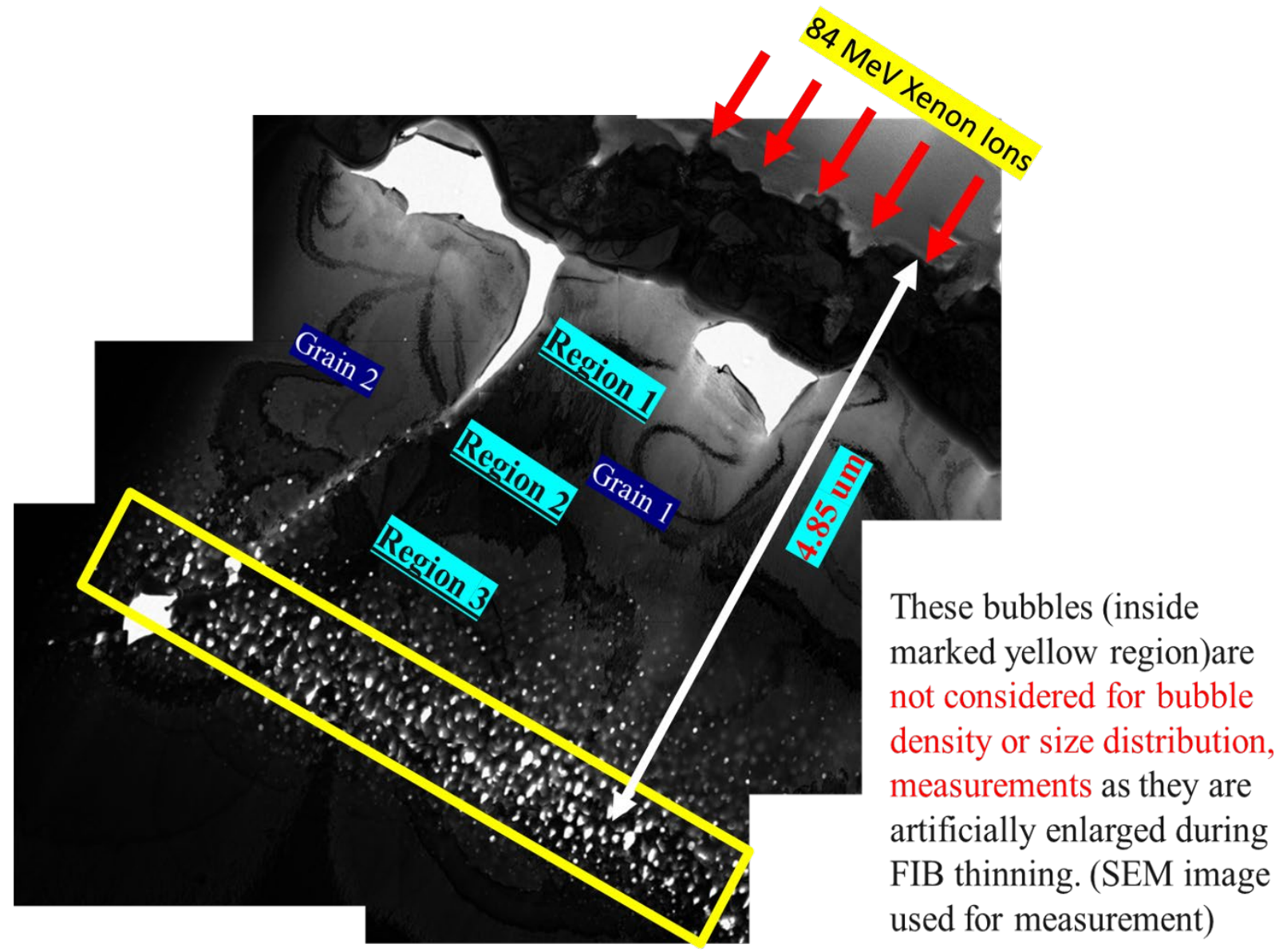

Figure 5: Bright field image of the U-10Mo TEM foil, where the red arrows indicate the Xe ion beam orientation over the sample during irradiation process and the white arrow indicates the region of the foil where the Xe ions have interacted and deposited $(\sim 4.85$ micrometer from top). Region 1, 2, \& 3 marked in blue are selected to study the bubble size distribution vs. specimen depth.

For gas bubble size distribution analysis of the U-10Mo sample irradiated at $450^{\circ} \mathrm{C}$ temperature, a part of the foil is selected where it is uniformly thick, thus delivering uniform illumination over the selected region of the sample, as shown in Figure 5. Following the SRIM calculation for Xe concentration with depth and corroborating the estimated depth for maximum Xe deposition from the bright field image, it can be said that at $\sim 4.85$ micrometer from top is the gas bubbles region (marked by yellow box). In order to calculate the bubble density and size variation with depth, the characterization was performed per Region 1, 2, \& 3 marked in blue (Figure 5). 

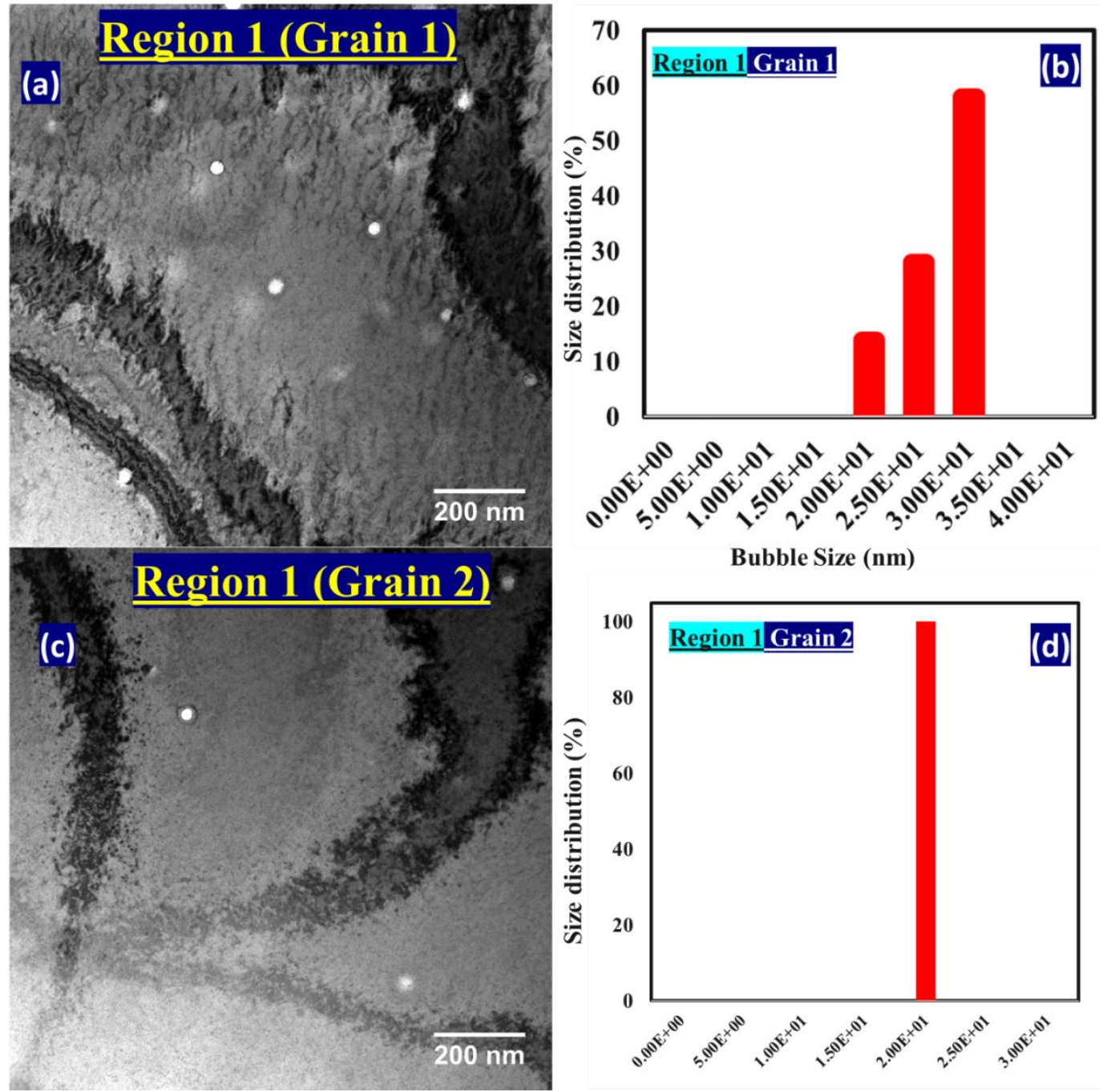

Figure 6: (a and c) Bright field image of the Region 1 of the TEM foil for two grains (1 and 2). In region 1 only large nano bubbles have formed and its corresponding bubble size distribution is presented in (b and $d$ ) where a monomodal size distribution of Xe bubbles in both Grain 1 and 2, with average size of $\sim 28 \mathrm{~nm}$. 


\subsubsection{Bubble Size Distribution and Density in Region 1}

The Xe bubbles formed in Region 1, for both grain 1 and 2 are all similar in dimension and sparsely distributed. The dimension of the bubbles present within this region ranges from $\sim 20 \mathrm{~nm}$ to $\sim 30$ $\mathrm{nm}$, and further details can be found in Figure 6 (a and c). The exact bubble size distribution (\%) details can be found in figure $6(\mathrm{~b}, \mathrm{~d})$. The estimated bubble density for this region is $\sim 7.84 \mathrm{E}+13$ /cc for whole area marked as Region 1.
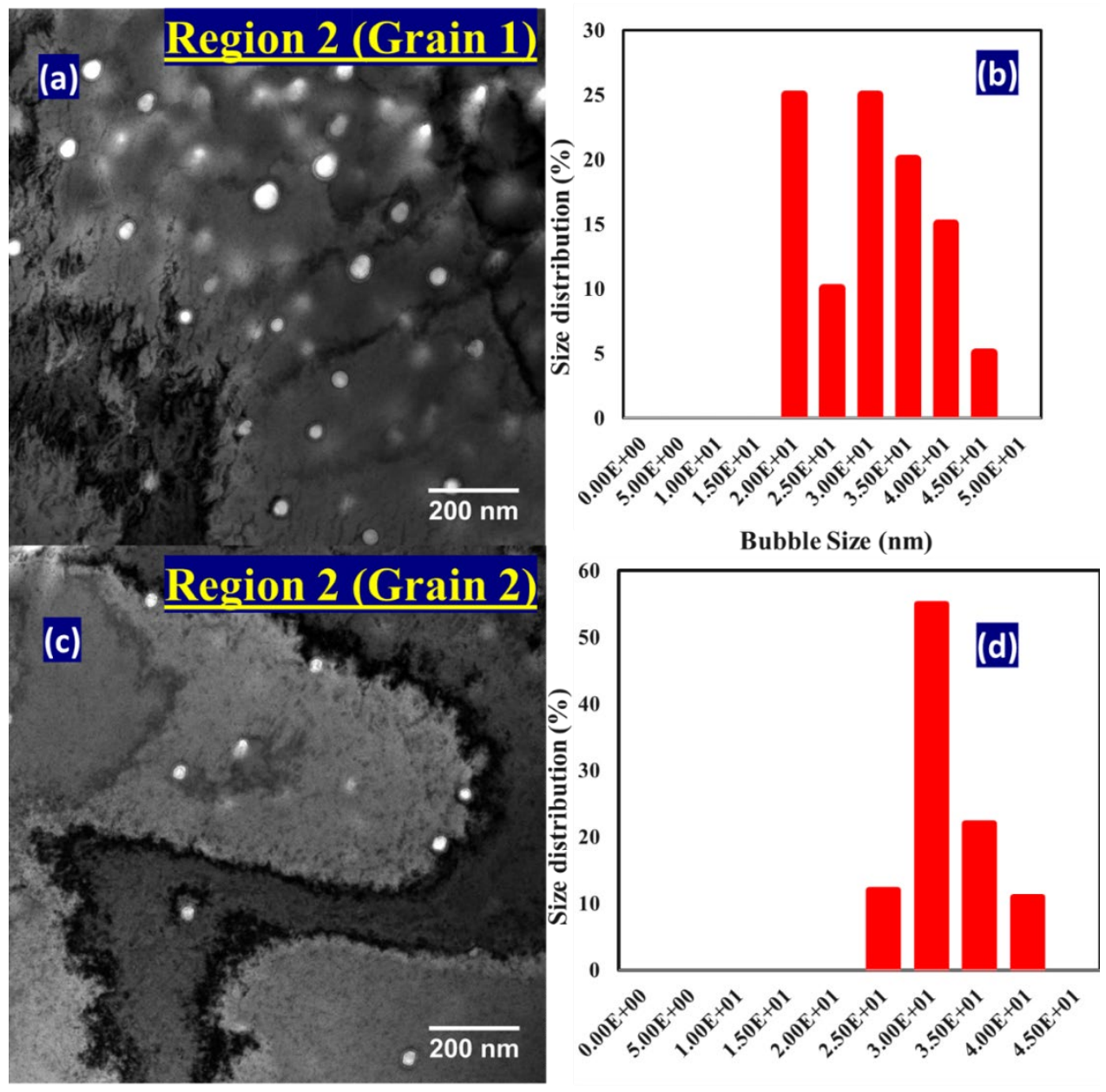

Bubble Size (nm)

Figure 7: (a and c) Bright field image of the Region 2 of the TEM foil for two grains (1 and 2). In region 2, only large nano bubbles have formed, and its corresponding bubble size distribution is presented in (b and $d$ ) where a monomodal size distribution of Xe bubbles in both Grain 1 and 2, with average size of $\sim 33 \mathrm{~nm}$. 


\subsubsection{Bubble Size Distribution and Density in Region 2}

The Xe bubbles formed in Region 2 are all similar in dimension and very sparsely distributed, especially in grain 2 area. All the bubbles present within the grains are of the dimension ranging from $\sim 20 \mathrm{~nm}$ to $\sim 45 \mathrm{~nm}$; details can be found in Figure 7 (a and c). The exact bubble size distribution (\%) details can be found in Figure 7 (b, d). The estimated bubble density for Grain 1 region is $\sim 2 \mathrm{E}+15 / \mathrm{cc}$ and for Grain 2 area it is $\sim 5 \mathrm{E}+14 / \mathrm{cc}$.

Region 3 (Grain 1)
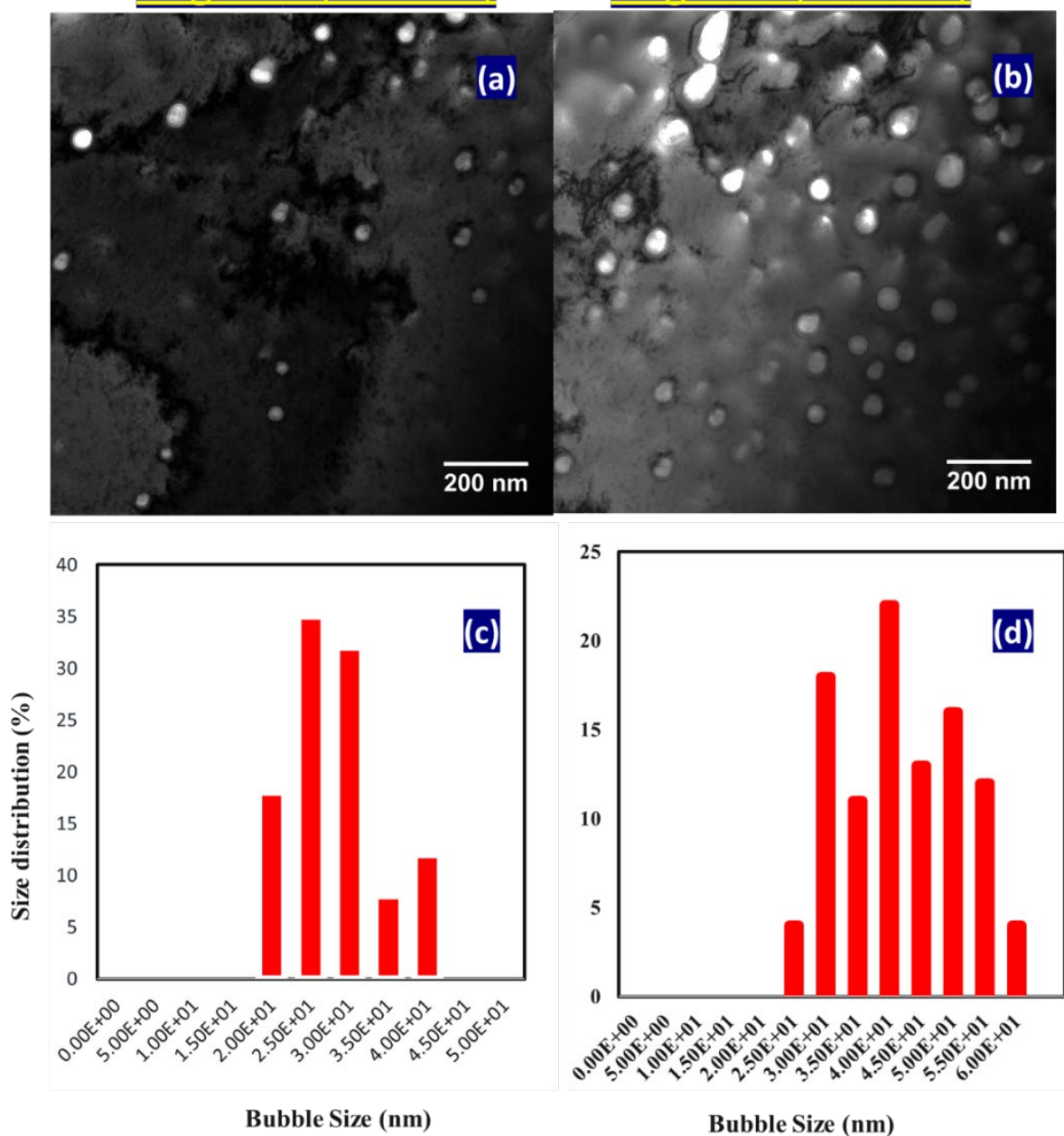

Region 3 (Grain 2)

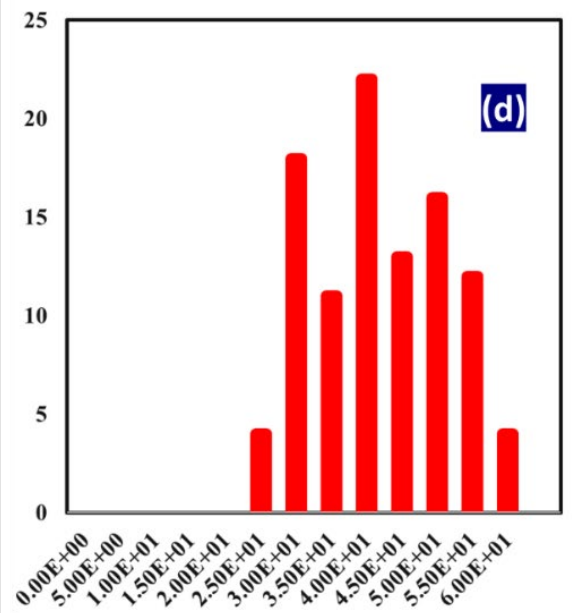

Bubble Size (nm)

Figure 8: (a and b) Bright field image of the Region 3 of the TEM foil for two grains ( 1 and 2). In region 3, even larger nano bubbles have developed. From Figure 8 (b) Grain 2 region has a higher density of bubbles than present in grain 1 (Figure 8 (a)). The corresponding bubble size distribution is presented in (c and $d$ ), where a monomodal size distribution of Xe bubbles in both Grain 1 and 2, with average size of $\sim 40 \mathrm{~nm}$. 


\subsubsection{Bubble Size Distribution and Density in Region 3}

The Xe bubbles formed in Region 3 are significantly larger in dimension compared to Region 2. In this case Grain 1 has a lower bubble density compared to Grain 2. All the bubbles present within the grains are of the dimension ranging from $\sim 20 \mathrm{~nm}$ to $\sim 60 \mathrm{~nm}$, details can be found in Figure 8 (a and b). The exact bubble size distribution (\%) details can be found in figure 8 (c, d). The estimated bubble density for Grain 1 region is $\sim 4 \mathrm{E}+15 / \mathrm{cc}$ and for Grain 2 area it is $\sim 6 \mathrm{E}+15 / \mathrm{cc}$.

\subsubsection{Bubble Size Distribution and Density in Highest Xe Deposition Region of U- 10Mo Specimen}

TEM has not been used for performing the analysis of the highest Xe deposition region. This is because this region has much larger bubbles compared to Regions 1, 2 and 3, and in particular during the thinning process via FIB those bubbles preferentially sputter off to artificially expand the dimension of the bubbles. This leads to the generation of triangular voids in the bubble regions. Therefore, as the bubbles are big enough to be observed using the TLD detector of the FIB SEM (Fig 9 (a)), using BSE, images of the whole bubble region were taken. In SEM, as back scattered electrons are emerging from the specimen matrix, chances are significant sub-surface features will be detected as if they are present on the surface. Therefore, to estimate the probable volume that the BSE electrons are emerging from, CASINO V2.5 was utilized to understand the working volume.

Using $10 \mathrm{KeV}$ electron beam as a source, and $17.24 \mathrm{~g} / \mathrm{cc}$ as U-10Mo density, the result showed only significant details are coming from a maximum depth of $300 \mathrm{~nm}$. Therefore, all the surface features with a dark circular spot (Figure 9 (a)) are present in the sub surface volume and should not be used to measure the diameter. The bubbles with defined boundary (regions around bubbles which have been cross sectioned, displaying a bright periphery showing due to possible charging issues or resulting from bubble wall stress) are utilized for measuring bubble dimension distribution in this zone. All the bubbles present within the grains are of the dimension ranging from $\sim 45 \mathrm{~nm}$ to $\sim 100 \mathrm{~nm}$, details can be found in Figure 9 (c). The estimated bubble density for this whole region is $\sim 1 \mathrm{E}+16 / \mathrm{cc}$. 
SEM back scattered electron (BSE) imaging
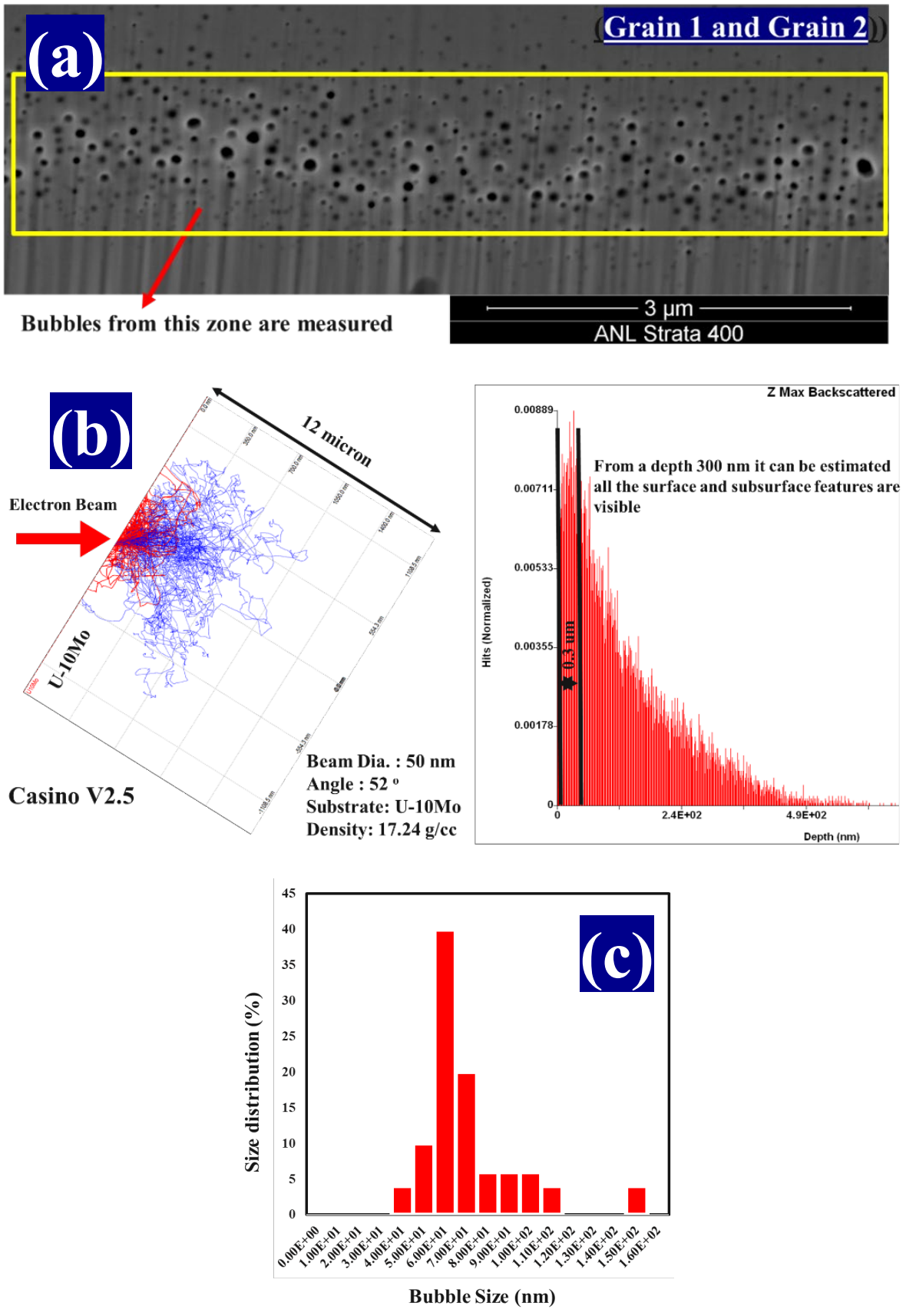

Figure 9: (a) BSE image of the highest Xe deposition zone representing both grains (1 and 2). (b) Schematic of electron working volume estimation using CASINO V2.5 software, based upon which it can be predicted that the SEM BSE detector will only detect electrons from a volume of $\sim 300 \mathrm{~nm}$ from the surface. (c) A bi-modal bubble size distribution of Xe gas bubbles is present. 


\subsubsection{Bubble Evolution at Temperature, $275^{\circ} \mathrm{C}$}

For gas bubble size distribution analysis of the U-10Mo sample irradiated at the $275^{\circ} \mathrm{C}$ temperature condition, a part of the foil was selected where it was uniformly thick, thus delivering uniform illumination over the selected region of the sample, as shown in Figure 10.

The overall microstructure for the U-10Mo specimen irradiated with $84 \mathrm{MeV}$ Xe ions at this temperature is shown in Figure 11. The TEM foil used for this analysis was $\sim 40 \mathrm{~nm}$ thick. With help of SADP analysis, it was found that the region is actually one large macro grain with orientation [001] respectively belonging to a BCC crystal structure.

Following the SRIM calculation for Xe concentration with depth and corroborating the estimated depth for maximum Xe deposition from the bright field image, it can be said that at $\sim 4.85$ micrometer from the top is the region excluded from bubble analysis due to FIB thinning effect (marked by yellow box). In order to calculate the bubble density and size variation with depth, the characterization was performed per Region 1, 2, \& 3 marked in blue (Figure 11).

For this particular case, the bubble distribution seems to be limited the highest Xe deposition zone. The bubbles are formed and present around $\sim 750 \mathrm{~nm}$ of the area for this sample (Figure 11). Therefore, the space just above the significantly observable subgrain boundary and the area below it is marked as Region 1, 2 and 3. 


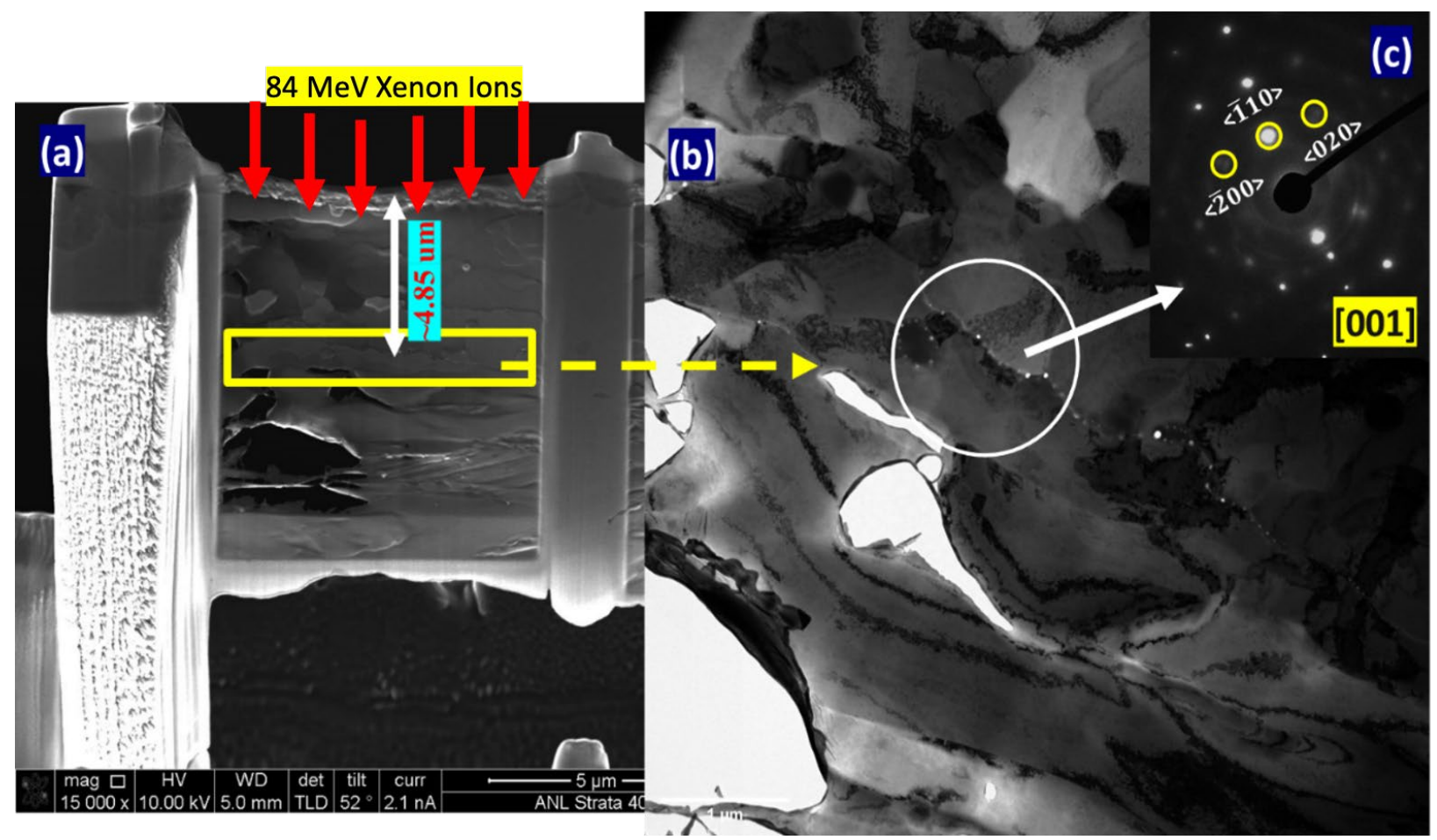

Figure 10: (a) BSE image of the TEM foil prepared for U-10Mo specimen irradiated at $275^{\circ} \mathrm{C}$. Red arrows indicate $84 \mathrm{MeV}$ Xe ion beam orientation over the sample during irradiation, and white arrow indicates total depth of $\mathrm{Xe}$ ions interaction and deposition zone. (b) SADP over bubble formation area, marked in white circle on the bright field image of the TEM foil. From analysis, it is found that orientation of this region [001], respectively, belongs to a $\mathrm{BCC}$ crystal structure (electron beam is perpendicular to sample).

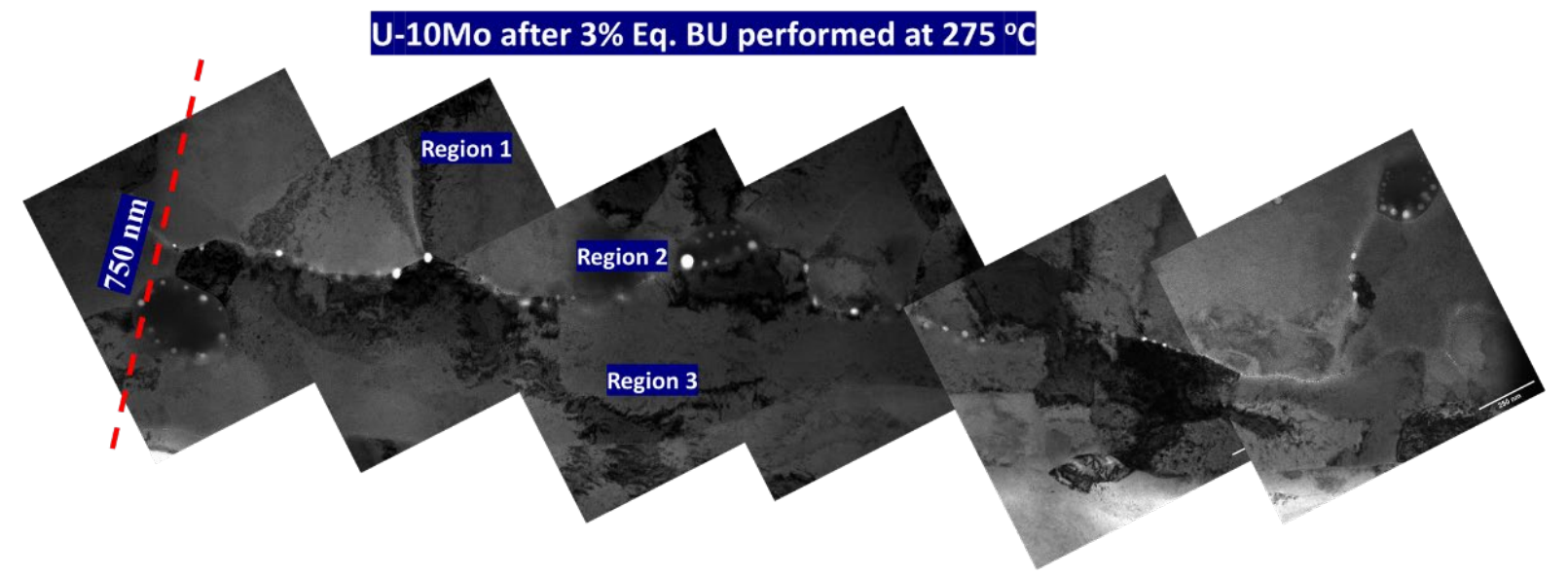

Figure 11: Composite image of the maximum Xe deposition area. The zone is $\sim 750 \mathrm{~nm}$ wide. The region above the subgrain boundary is identified as Region 1 , the subgrain boundary as Region 2 and the space below as region 3. 

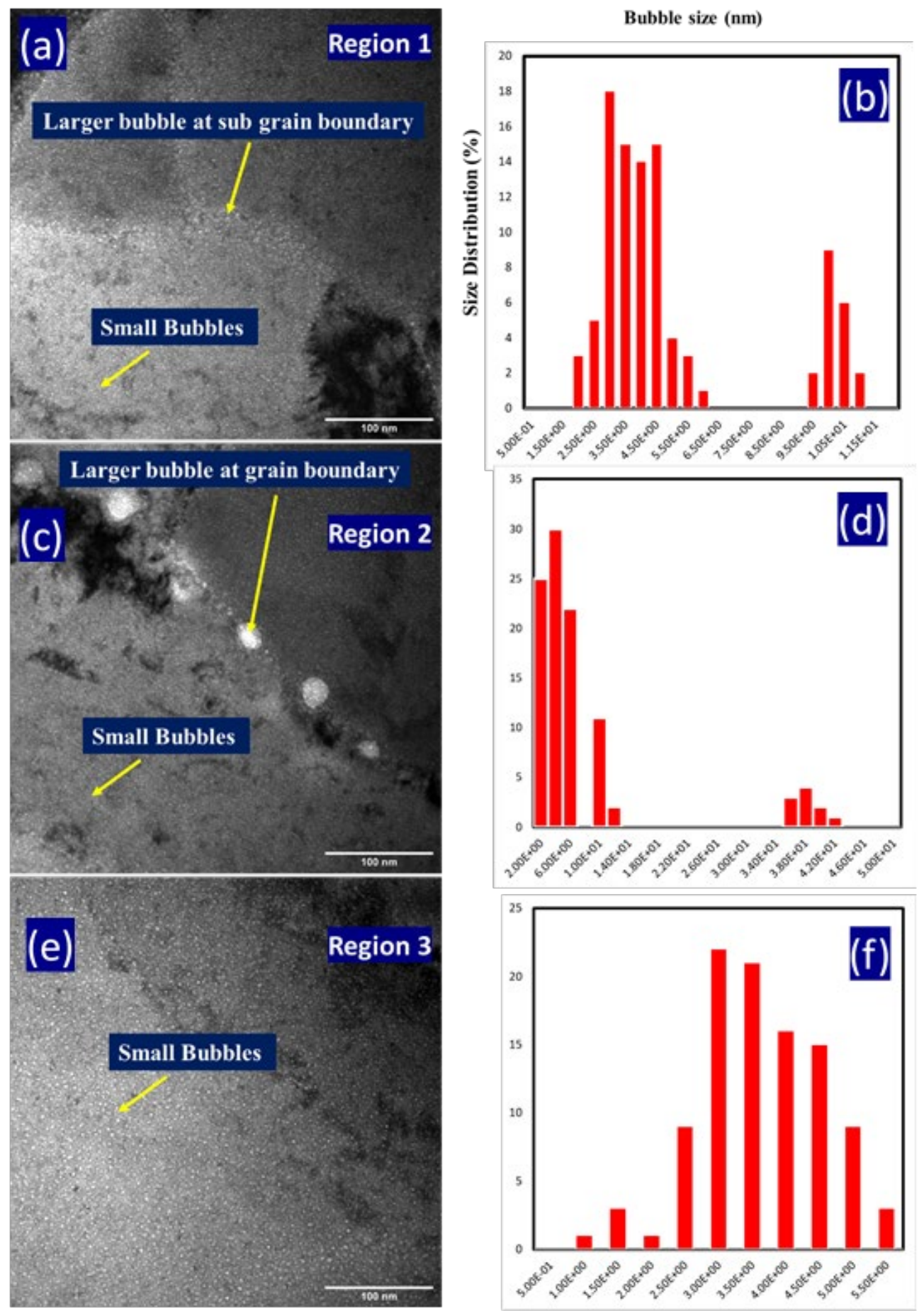

Figure 12: (a, c and d) Bright field image of the Region 1, 2 and 3. Small and large nano bubbles are observed. In region 2 , large bubbles have formed around the sub grain boundary area. In $(b, d, c)$ The corresponding bubble size distribution is presented for the three regions, where for region 1 and 2 definite bimodal Xe bubble size distribution is seen and for region 3 it is showing a monomodal distribution. 


\section{Future Work}

In-depth further analysis of the $275^{\circ} \mathrm{C}$ irradiated U-10Mo specimen is necessary, such as elemental characterization studies, using as HAADF and EELS performed in TEM. This will be beneficial for better understanding the bubble formation and coarsening. This test will verify whether any phase separation/decomposition is occurring at higher temperature. Detailed studies in regard to the dislocation formation and its effect over bubble morphology should be also performed. Additional swift ion irradiation tests at different doses (in steps) at the same temperature is also necessary to develop the understanding regarding the gas bubble formation, evolution and agglomeration.

\section{Conclusions}

In this study, $84 \mathrm{MeV}$ swift Xe ion irradiation was used to implant Xe ions in U-10Mo binary metallic fuel at $450^{\circ} \mathrm{C}$ and $275^{\circ} \mathrm{C}$ to simulate fission gas behavior of this fuel during in-pile irradiation. From the post irradiation examination analysis, it can be concluded at $450^{\circ} \mathrm{C}$, with same amount of dose received as $275^{\circ} \mathrm{C}$ the $\mathrm{Xe}$ gas bubbles, seems to coarsen more easily compared to $275^{\circ} \mathrm{C}$. This is evident from the consistently bigger bubble size distribution for the $450^{\circ} \mathrm{C}$ sample starting from Region 1 through Region 3. The results generated for fission gas bubble evolution observed in this study can be used to support fuel candidate down-selections and fuel performance models for U-xMo fuel systems.

\section{Acknowledgement}

This work was sponsored by the U.S. Department of Energy, Office of Nonproliferation Research and Development in the U.S. National Nuclear Security Administration Office of Defense Nuclear Nonproliferation under Contract DE-AC02-06CH11357. 


\section{References}

[1] A. M. Yacout, in AIP Conference Proceedings, volume 2160, AIP Publishing LLC, p. 050004.

[2] M. Pellin, A. M. Yacout, K. Mo, J. Almer, S. Bhattacharya, W. Mohamed, D. Seidman, B. Ye, D. Yun, R. Xu, et al., Journal of nuclear materials 471 (2016) 266-271.

[3] J. F. Ziegler, M. D. Ziegler, J. P. Biersack, Nuclear Instruments and Methods in Physics Research Section B: Beam Interactions with Materials and Atoms 268 (2010) 1818-1823.

[4] R. E. Stoller, M. B. Toloczko, G. S. Was, A. G. Certain, S. Dwaraknath, F. A. Garner, Nuclear instruments and methods in physics research section B: beam interactions with materials and atoms 310 (2013) 75-80.

[5] B. Beeler, Y. Zhang, M. Okuniewski, C. Deo, Journal of Nuclear Materials 508 (2018) 181194. 


\section{Argonne $\mathbf{A}$}

\section{Nuclear Science \& Engineering Division}

Argonne National Laboratory

9700 South Cass Avenue, Bldg. 208

Argonne, IL 60439

www.anl.gov 